\title{
Actividades da Comissão Europeia de Promoção da Utilização de Tecnologias Limpas do Carvão
}

\section{SAMUELE FURFARI*}

\section{A ELECTRICIDADE E O CARVAO NA CENA ENERGÉTICA}

A electricidade assumiu um papel tão importante desde 0 início do presente século, que não surpreende 0 facto de a sua importância ser por vezes comparada à que tinha o fogo, há muitos séculos atrás. É, pois, natural, que uma das principais preocupações no contexto da questão energética seja a produção de electricidade, e é precisamente nesta área que 0 debate sobre a energia se revela frequentemente mais emocional do que racional. 0 desenvolvimento recente (se visto à escala da era industrial) da ecologia veio criar demasiadas expectativas que, pelo menos a curto prazo, só muito dificilmente poderão ser concretizadas. Sem dúvida que deverão ser desenvolvidos todos os esforços no sentido de atingir estes objectivos, mas é também necessário chamar a atenção da opinião pública, não só para 0 facto de que tal não poderá ser feito imediatamente, como ainda para os custos inerentes. De facto, a protecção ambiental envolve custos, que deveremos estar dispostos a suportar.

Todos os esforços desenvolvidos no sentido da introdução das novas energias renováveis ainda não se traduziram em alterações significativas, isto apesar das iniciativas tomadas por todos os países membros da OCDE e, em particular, da UE. Se observarmos o saldo energético global da UE, constataremos que as novas energias renováveis representaram, em 1991, 3,24 Mtep, ou seja, $0,28 \%$ do consumo total de energia (de notar que a maior fracção deste valor se refere à energia produzida a partir da biomassa). Quanto à vertente da produção de electricidade, a situação não é diferente - a Figura 1 ilustra a distribuição da capacidade de produção de electricidade na UE.

As centrais térmicas concentram actualmente a maior parte da produção de electricidade $(57,6 \%)$, sendo ainda de destacar o papel de relevo atingido pelo

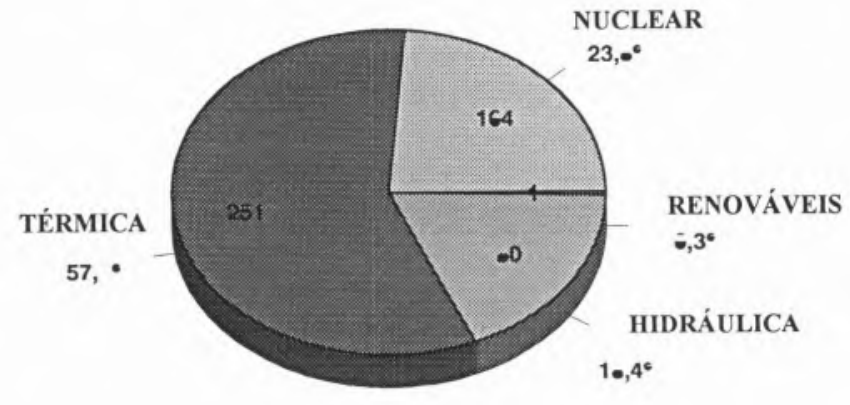

Figura 1 - Capacidade de produção de electricidade na UE (1991 — Dados da Comissāo)

nuclear na UE, enquanto recurso energético $(23,8 \%)$, isto graças ao empenhamento da França e, também, de outros países membros. No entanto, e à escala mundial, o sector nuclear representa apenas $14,7 \%$ do total da electricidade produzida; da fracção restante, é óbvio que uma grande parte depende dos combustiveis fósseis sólidos, ou seja, o carvão e a lenhite.

0 consumo industrial e doméstico de combustíveis sólidos será cada vez mais limitado, já que se manterão, naturalmente, as diversas vantagens do gás natural sobre os mesmos. Contudo, no campo da produção de electricidade, 0 carvão e outros combustiveis sólidos continuarão a desempenhar um papel de relevo - as centrais a carvão satisfazem actualmente $40 \%$ da procura mundial de electricidade,

consumindo, entretanto, mais de metade da produção mundial de carvão.

Elaboradas pela Comissão, as previsões relativas à utilização de energia até aos anos 2000 e 2005 foram apresentadas, em Setembro de 1992, à Conferência Mundial de Energia, realizada em Madrid. 0 cenário considerado abrangeu os aspectos económicos associados à oferta e os custos relativos dos diversos combustiveis, sem esquecer as preocupações de carácter ambiental. Os números avançados para os anos $2000 \mathrm{e}$ 2005, relativamente às necessidades em carvão da União Europeia, situam-se na ordem das 279 Mtep.

Quanto à produção de electricidade, trata-se de um sector em franco crescimento (média de 2,0\% por ano até 2005 , com aproximadamente $2,4 \%$ por

Figura 2 - Produção de electricidade na União Europeia por tipo de recurso energético

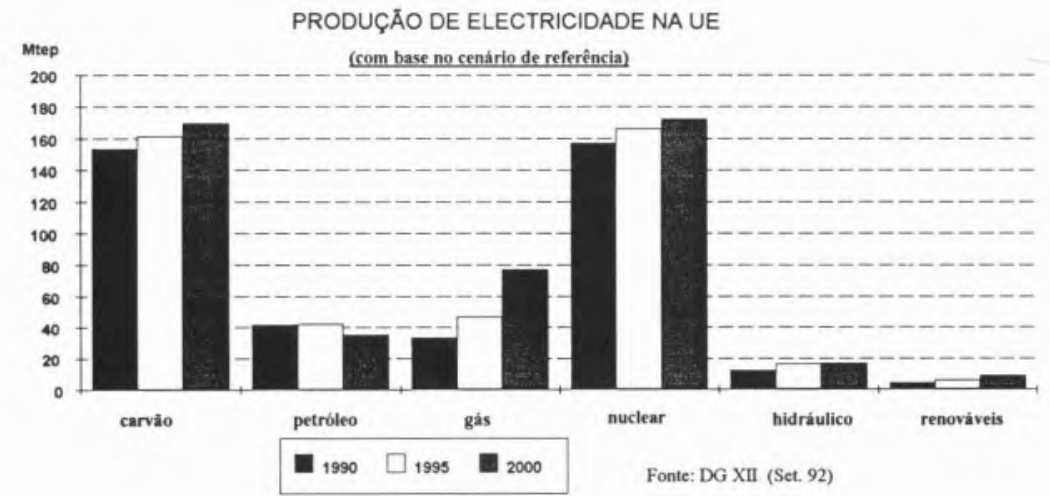


ano até meados da presente década); de notar que, em 1990, a electricidade representou, na União Europeia, cerca de $18 \%$ do consumo energético final. No que se refere à utilização de carvão nas centrais eléctricas (ver a Figura 2), apesar de uma subida de $144 \%$ no consumo de gás entre 1990 e 2000, o carvão e a lenhite continuarão a responder por uma grande parte da crescente procura de electricidade prevista para os países membros da UE.

As análises individualizadas para cada um dos estados membros indicam tratar-se de uma tendência generalizada (ver Figura 3). Naturalmente que a dependência do carvão será mais importante nos países que tradicionalmente recorrem a este combustivel.

Na Dinamarca - um dos estados membros mais avançados no domínio da protecção ambiental - cerca de $92,5 \%$ da electricidade é produzida a partir de carvão importado. 0 Reino Unido, pelo seu lado, constitui o único exemplo de redução (a partir de 1995) do consumo deste produto, em consequência, aliás, da decisão de construir novas centrais de ciclo combinado a gás natural. Contudo, no contexto da presente conjuntura energética deste país, e tomando em consideração a problemática do sector mineiro, não é de excluir a hipótese de que esta restruturação se venha a revelar menos marcante que 0 inicialmente previsto.

Uma das principais vantagens do carvão assenta na existência de grandes reservas mundiais espalhadas por diversas regiões do globo, as quais garantem a fiabilidade dos fornecimentos (aliás, as importações da União Europeia já começaram a aumentar). A lenhite continuará a ser utilizada na maioria da centrais eléctricas da Grécia, país em que este combustivel representa cerca de $79 \%$ da electricidade produzida. Quanto à Alemanha, as previsões apontam para uma quebra acentuada do consumo deste último produto; de facto, enquanto na parte ocidental do país este continuará a ser utilizado em centrais equipadas com sistemas de dessulfuração dos gases de combustão, já na antiga RDA, após o recente colapso, se forem retomados os padrões normais de consumo de electricidade, os custos proibitivos associados à reconversão das centrais segundo critérios de protecção ambiental farão assim desviar as atenções para outros combustiveis.

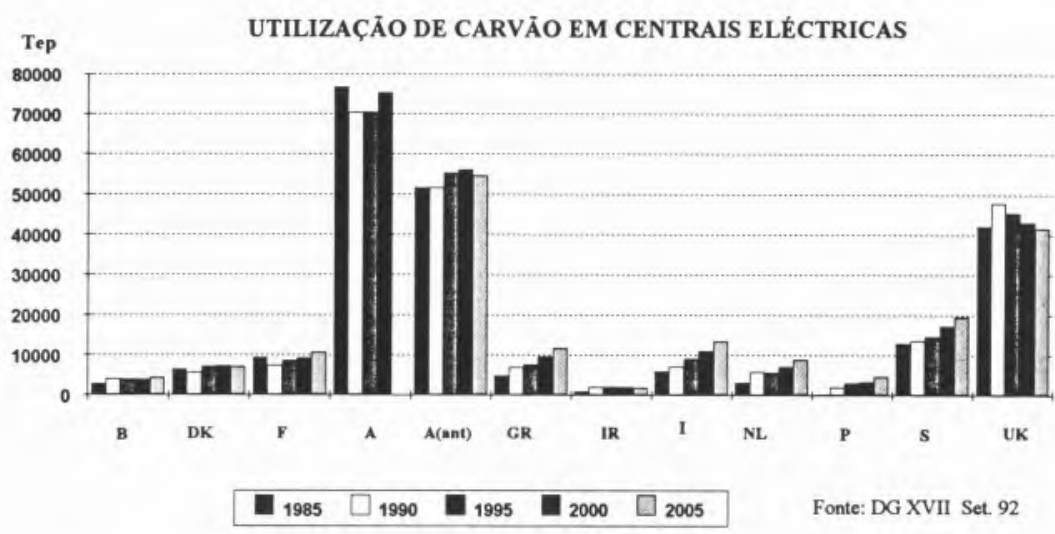

Figura 3 - Utilização de carvão nas centrais eléctricas dos Estados Membros

A influência da Taxa proposta sobre a Energia/Carbono foi alvo de um estudo recente por parte da DirecçãoGeral de Energia da Comissão. Aparentemente, este instrumento fiscal iria exercer um efeito limitado sobre a selecção de combustiveis para produção de electricidade. De facto, a aplicação da referida taxa sobre estes factores de produção de electricidade traduzir-se-ia por um aumento mais pronunciado do custo dos combustiveis sólidos, logo seguido pelos do petróleo combustivel e do gás, o que deveria conduzir a uma diminuição da utilização dos primeiros. Entretanto, se estabelecermos uma comparação com 0 cenário de referência, 0 consumo de combustiveis sólidos na produção de electricidade diminuiria apenas em cerca de $2,0 \%$, no ano 2000 , enquanto a procura de petróleo e de gás registaria uma redução de $1,9 \%$ e $1,5 \%$, respectivamente. Assim, o sector da produção de electricidade não acusaria, por volta do ano 2000 , uma reacção marcada à taxa proposta. Quanto às emissões de $\mathrm{CO}_{2}$, a redução deveria ser ligeiramente inferior a $2 \%$ (ver Figura 4).

Uma das razões subjacentes a esta

evolução é o facto de a parte da taxa que incide sobre a energia ser aplicada como uma taxa média sobre combustíveis, quer fósseis, quer nucleares, limitando assim 0 agravamento dos preços dos combustiveis utilizados em centrais com rendimentos energéticos mais baixos; tal situação não constituiria, pois, um estímulo para a substituição dos combustíveis. Além disso, há a considerar que a vida útil das centrais eléctricas atinge várias décadas, pelo que 0 tempo disponivel até ao ano 2000 se revela claramente insuficiente (noutros sectores, os ritmos de substituição dos equipamentos consumidores de energia são muito mais elevados). Finalmente, o caso de referência contempla já uma transferência maciça do sector da produção de electricidade para 0 gás natural, deixando assim uma pequena margem, caso a taxa venha a ser aplicada, para a construção de novas instalações a gás em substituição dos sistemas mais antigos caracterizados por elevadas emissões de $\mathrm{CO}_{2}$.

No que diz respeito ao padrão de utilização de combustiveis na União Europeia, prevêem-se, para o horizonte do ano 2000 , algumas transferências para com-

Figura 4 - Influência na UE da Taxa proposta sobre Energia/ $\mathrm{CO}_{2}$

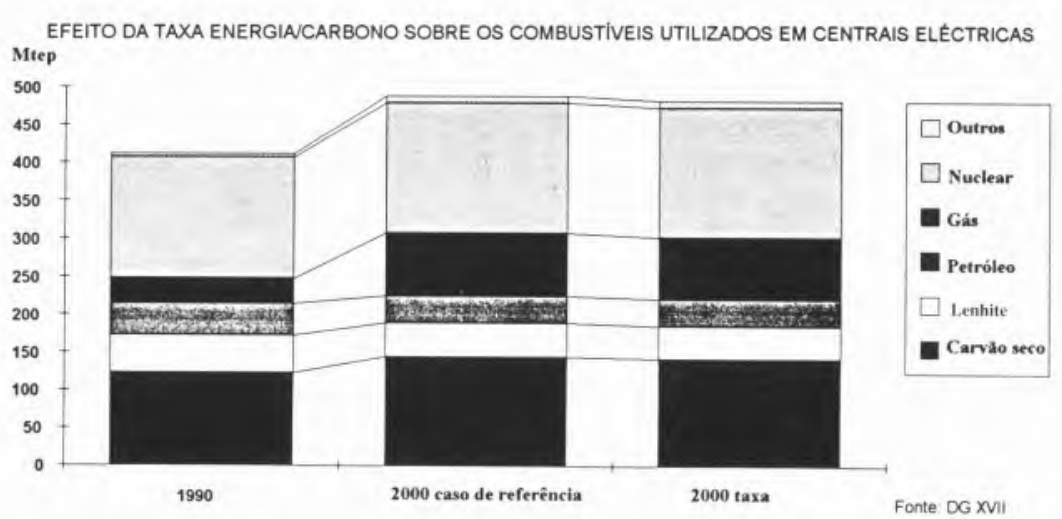




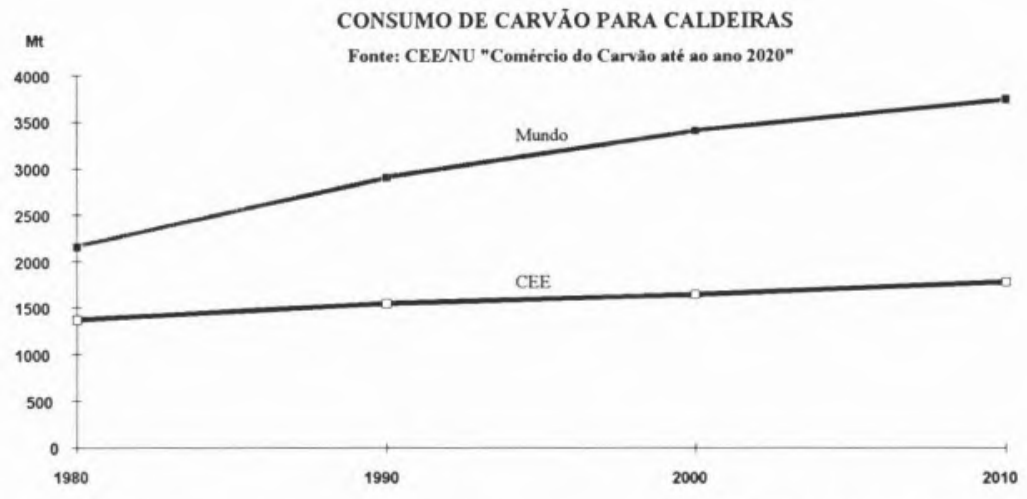

Figura 5 - Consumo mundial e europeu de carvão (em Mtec) em centrais eléctricas

bustiveis com baixos teores de carbono, as quais poderão ser mais pronunciadas no próximo século, quando as instalações existentes atingirem o fim da sua vida útil ou tiverem sido já substituídas por tecnologias de baixa emissão de $\mathrm{CO}_{2}$.

0 estudo da Comissão não é 0 único a destacar estas tendências. Na verdade, também o relatório "Comércio do Carvão até ao ano 2010", publicado, em Março de 1992, pela Comissão Econó-mica para a Europa das Nações Unidas (ver Figura 5), defende que 0 carvão continuará a desempenhar, nos próximos anos, um papel da maior importância (menos na Europa do que no resto do mundo). Assim, é legítimo concluir que, relativamente ao campo das tecnologias limpas do carvão, existe uma margem para o desenvolvimento do mercado e de novos produtos.

Embora reconhecendo a inquietação gerada pelo potencial impacto ambiental da emissão atmosférica de gases resultantes da combustão de volumes tão elevados de carvão, a concorrência de outros combustíveis (em particular, o gás natural) e, em muitos casos, a dificuldade de obtenção de financiamento para novas centrais, a Agência Internacional de Energia mantém que, até ao final do presente século, o consumo global de carvão crescerá a um ritmo anual de $1,5 \%$. Nas centrais eléctricas, 0 crescimento do consumo será, em princípios do próximo século, de aproximadamente $3.000 \mathrm{Mt} / \mathrm{ano}$. 0 carvão continuará a responder por cerca de $40 \%$ da produção mundial de electricidade (ver Figura 6).

Figura 6 - Produção mundial de electricidade em 1988 e 2000 ("Utilização de carvão em centrais eléctricas perspectivas atẻ ao ano $2000^{\circ}$. AIE - Estudos sobre o carvã̃o - Out.91)
0 aumento do recurso ao carvão, incluindo 0 destinado às centrais eléctricas, ocorrerá principalmente em paises em vias de desenvolvimento, como a China ou a União Indiana, pelo que se torna óbvia a necessidade de garantir 0 acesso destes países às tecnologias mais avançadas de combustão de carvão (instalações eficientes e pouco poluidoras), assim como a concessão dos correspondentes apoios financeiros e políticos. Mas, também nos países desenvolvidos, e apesar das críticas levantadas nos últimos anos, com base em argumentos, quer ambientais, quer económicos, a opinião generalizada é que 0 consumo de

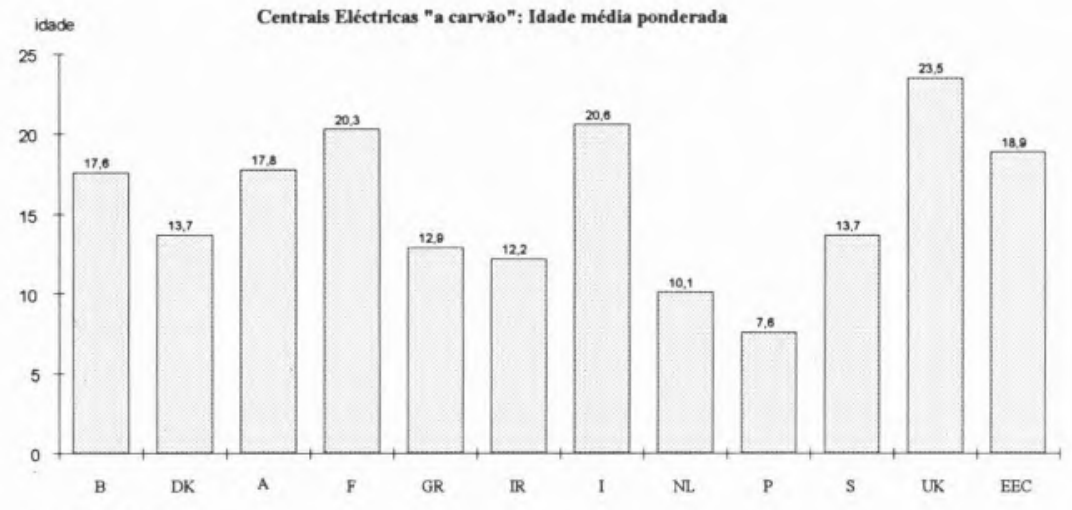

Fonte: $\mathrm{EPIC} \mathrm{e} \mathrm{CE}$

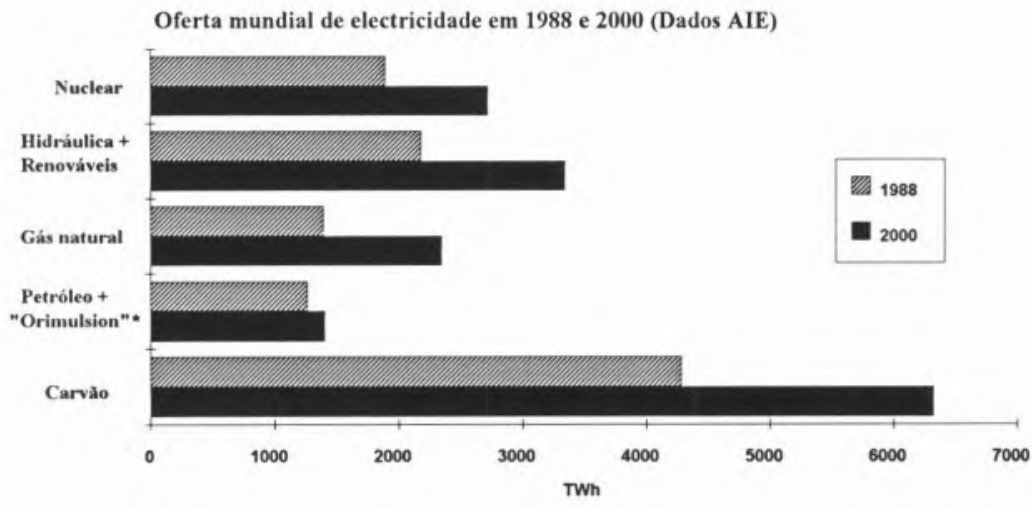

carvão, lenhite incluída, deverá aumentar ao longo das próximas décadas.

A irradicação progressiva do carvão não constitui uma opção economicamente viável: embora seja inegável que o gás natural se tornou num combustivel atraente e que a energia nuclear representa uma alternativa potencial, face aos volumes necessários e aos problemas inerentes a estes dois recursos energéticos, não parece viável, nem política, nem economicamente, abdicar da utilização de carvão em centrais eléctricas. Assim, tanto na União Europeia, como em muitos outras partes do mundo, continuarão a ser consumidos grandes volumes de carvão e de lenhite, sendo, por conseguinte, da maior importância garantir que a combustão destes produtos se processa da forma mais eficiente e limpa possivel.

Mas, mesmo que estas perspectivas optimistas não se concretizem, tal não excluirá a necessidade de substituição das instalações que se tornem obsoletas num futuro próximo. A Figura 7

Figura 7 - Idade média ponderada das centrais eléctricas a carvăo na União Europeia, em 1992 (Dados daComissão) 
apresenta as idades médias para os vários estados membros (valores ponderados com base na dimensão das unidades), as quais nos permitem constatar que, no início do próximo século, uma grande parte da capacidade instalada terá atingido o fim da vida útil; nessa altura, para que 0 carvão possa continuar a constituir uma opção, será necessário recorrer a tecnologias mais limpas e menos dispendiosas.

A Direcção-Geral de Energia da Comissão crê ser necessário prosseguir 0 desenvolvimento e 0 ensaio de novas tecnologias que permitam a utilização económica e limpa do carvão e, em particular, demonstrar a eficácia das mesmas a uma escala suficientemente grande para persuadir o sector da produção de electricidade da justificação dos volumosos investimentos inerentes; é nesta perspectiva que este organismo continua a apoiar 0 desenvolvimento e a demonstração de novas tecnologias na União Europeia. Na medida em que uma grande parte do carvão utilizado se destina às centrais eléctricas e que os custos de novas unidades (especialmente se de concepção moderna) são elevados, é compreensivel que muitos dos esforços desenvolvidos visem novos conceitos de produçāo de electricidade.

\section{O CARVÃO E 0 AMBIENTE}

Independentemente da questão do dióxido de carbono, já referida a propósito da Taxa sobre Energia/Carbono, o carvão e os produtos minerais a ele associados contêm elementos potencialmente poluidores que, na sequência de uma combustão ou gaseificação, podem ser libertados para a atmosfera. As tecnologias de prevenção destas emissões atmosféricas são, hoje, bem conhecidas (e de aplicaçāo generalizada), pelo que nada obriga a que à combustão do carvão esteja associada a produção de fumos.

Na União Europeia, os níveis de emissão de compostos silicados e poeiras que acompanham os gases de combustão de todas as caldeiras e fornalhas a combustiveis fósseis săo, actualmente, regulamentados. De referir, também, que se encontra já disponivel toda uma série de dispositivos de remoção de poeiras e compostos silicados produzidos pela combustão e gaseificação de carvão e lenhite - ciclones, precipitadores elec- trostáticos, depuradores por via húmida e filtros - capazes de responder às normas vigentes e às que, provavelmente, serão impostas no futuro. Embora continuem a ser alvo de estudos visando 0 seu aperfeiçoamento (também aqui, a Comissão concede 0 seu apoio), estes métodos garantem, desde já, que, em futuras centrais a combustivel sólido, operadas sob condições correctas, os produtos de combustão acima referidos não constituirão um problema.

Naturalmente que é necessário considerar 0 destino a dar às cinzas recolhidas, evitando, simultaneamente, impactos ambientais negativos. Nalguns casos, em particular no que se refere às centrais eléctricas a combustivel pulverizado, as cinzas podem ser utilizadas na construção civil, nomeadamente, no enchimento de estruturas, no fabrico de blocos de construção ou como substituto do cimento no betão. Nas caldeiras de leito fluido, a adição de calcário ao combustivel, com o objectivo de reter 0 enxofre (processo abordado mais adiante), embora contribua para aumentar 0 volume dos residuos, confere-lhes, também, propriedades de auto-endurecimento, o que constitui uma vantagem. Desde há anos que a Comissão tem vindo a apoiar estudos sobre a aplicação e eliminaçăo de cinzas e, presentemente, apoia, no âmbito do programa THERMIE, 0 estudo de um processo de extinção da cal contida em cinzas parcialmente dessulfitadas produzidas por caldeiras a carvão, visando a obtenção de um produto aplicável no fabrico de cimento.

0 carvão e 0 petróleo contêm frequentemente compostos de enxofre que, na sequência do processo de combustāo, libertam dióxido de enxofre para a atmosfera. Este pode ser devolvido à superfície, normalmente através da chuva, provocando a acidificação de solos, lagos e cursos de água, com os consequentes danos para florestas e espécies aquáticas. As emissões de dióxido de enxofre, com origem em centrais a carvão, podem ser reduzidas por meio de três métodos: limpeza do carvão; tratamento durante a combustão; e remoção do dióxido de enxofre depositado nas condutas de fumo e dessulfuração dos gases de combustão.

A limpeza do carvão constitui um método capaz de remover apenas entre $5 \%$ e $30 \%$ do enxofre, já que o restante se encontra integrado na própria estrutura química do carvão, logo não sendo passivel de remoção por processos físicos, como a lavagem. Quanto aos métodos de dessulfuração dos gases de combustão, estes são amplamente utilizados em todo 0 mundo em centrais a carvão pulverizado, apesar de os custos de investimento e de exploração dos sistemas complementares onerarem o preço da electricidade ou do calor produzidos.

Por conseguinte, muitos dos esforços desenvolvidos neste campo têm visado os processos em que o enxofre é removido das cinzas ainda no interior do sistema de combustâo ou noutro reactor (mais adiante, serão abordados exemplos destas tecnologias "limpas do carvão", objecto do apoio da Comissão).

Quer os óxidos de azoto resultantes da combustão de combustiveis fósseis, quer os hidrocarbonetos emitidos, sobretudo, nos gases de escape dos veiculos automóveis, podem, quando expostos à luz solar, dar origem à formação de ozono, o qual tem sido responsabilizado por danos em árvores, na Europa Central. De referir, também, que estes gases contribuem para o fenómeno das chuvas ácidas. Se em todos os processos de combustão são normalmente produzidos óxidos de azoto, na sequência da reacção do azoto com 0 oxigénio do ar, às altas temperaturas desenvolvidas, no caso do carvão, a formação destes óxidos é ainda maior devido à oxidação dos compostos azotados presentes neste combustivel. Várias técnicas permitem reduzir a emissão de óxidos de azoto na combustão do carvão; embora seja possivel proceder à sua remoção dos gases de combustão, a maior parte dos métodos baseia-se na alteração das caracteristicas de combustão na fornalha (mais adiante, será também abordado 0 trabalho desenvolvido pela Comissão nesta área).

Relativamente a alguns combustiveis sólidos, há também que levar em conta a libertação para a atmosfera, na sequência da combustão, de pequenas quantidades de elementos vestigiais, como sejam o chumbo, 0 cádmio e 0 arsénio. No entanto, a maior parte dos mesmos é retida nas cinzas, pelo que, à medida que aumentar a eficiência dos sistemas de remoção de poeiras -em paralelo com o crescente rigor das normas aplicáveis - a emissão destes elementos continuará a registar uma diminuição.

Voltando à problemática do $\mathrm{CO}_{2}$, há que referir que na combustāo de todos os combustiveis fósseis é liberta- 
do dióxido de carbono, composto responsável por cerca de metade do chamado "efeito de estufa", para o qual concorrem igualmente 0 metano, 0 óxido nitroso e os clorofluorocarbonetos produzidos pelas actividades do homem. A emissão destes gases pode pôr em causa 0 equilibrio natural da atmosfera, provocando a alteração de padrões climatéricos (temperaturas, ventos e chuvas) e a subida do nível dos oceanos.

Não existem dados concretos relativamente à escala temporal e à magnitude do fenómeno de aquecimento global provocado pela emissão atmosférica destes gases, nem tão pouco sobre 0 impacto da redução das emissões de dióxido de carbono resultantes da combustão do carvão. De qualquer forma, esta é uma questão que sai fora do âmbito do presente trabalho.

Embora a combustão do carvão represente mais de $40 \%$ da electricidade produzida em todo mundo, contribui apenas para $8 \%$ do potencial "efeito de estufa". Na UE, as centrais eléctricas a carvão e os veículos automóveis são os principais responsáveis pelas emissões de $\mathrm{CO}_{2}$ (ver Figura 8), pelo que deverão constituir o principal alvo das iniciativas a tomar. são avançou com a proposta da já referida Taxa Energia/ $\mathrm{CO}_{2}$. A remoção do dióxido de carbono dos gases de combustão e - aspecto que levanta mais dificuldades - a respectiva armazenagem por forma a que não se escape para a atmosfera é alvo de estudos com vista a uma solução de longo prazo. Em alternativa, a única forma viável de limitar a libertação deste composto quando da combustão do carvão, consiste na melhoria da eficiência do processo de conversão da energia química do carvão em calor, electricidade ou outra forma intermediária de energia, abordagem que, aliás, encerra outras vantagens a nivel de redução dos custos da energia $e$ de aumento da competitividade deste tipo de combustivel. Nas secções seguintes, serão apresentados exemplos de como as tecnologias "limpas do carvão" apoiadas pela Comissão contribuem para aumentar 0 rendimento energético das centrais e diminuir as emissões de dióxido de carbono.

\section{O APOIO DA UE AO CARVÃO ATÉ 1989}

Desde a década de 1950 , que a União Europeia tem vindo a prestar 0 seu

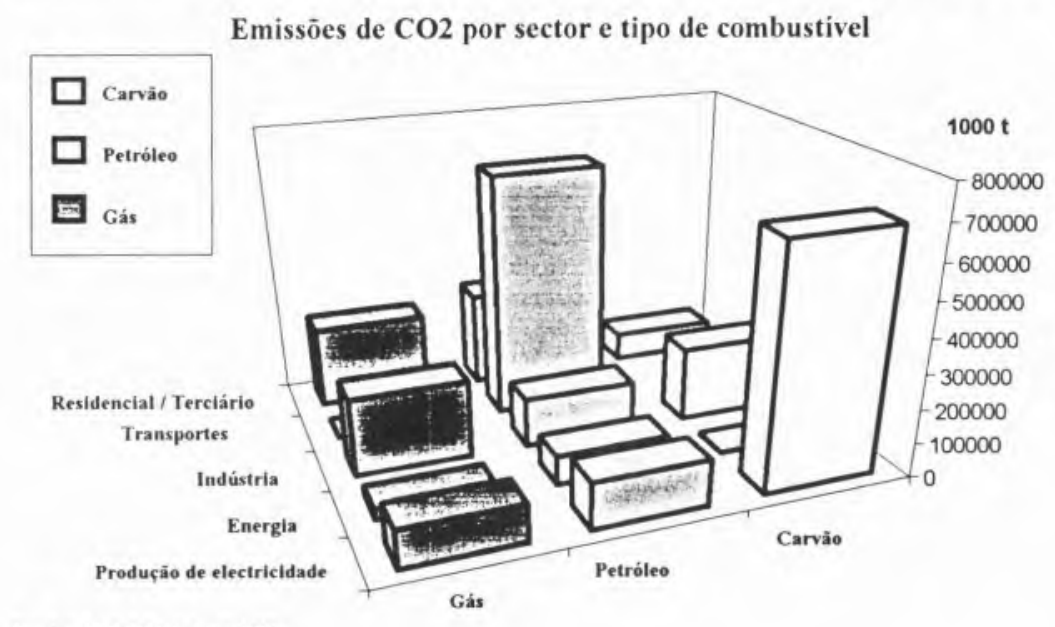

Fonte: DG XVII (Jan.92)

Figura 8 - Emissōes de $\mathrm{CO}_{2}$ na UE, segundo os sectores económicos e os tipos de combustivel

No reconhecimento da necessidade de, como medida de prudência, reduzir as emissōes de dióxido de carbono resultantes da combustão de combustíveis sólidos, no contexto de um leque mais alargado de medidas tendentes a limitar a emissão de gases que concorrem para o "efeito de estufa", a Comis- apoio à pesquisa, desenvolvimento e demonstração de novos processos de produção e utilização de carvão e outros combustiveis sólidos. Na sequência das crises petrolíferas dos anos 70 , foi criado o Programa de Demonstração Energética da UE, implementado em 1978, o qual visava apoiar a demonstração das tecnologias de liquefacção e gaseificação do carvão. Em 1983, este programa seria alargado à área da combustão.
Entre 1978 e 1989, a EU apoiou diversos projectos, atribuindo subsídios no valor total de 302 milhões de ECU, dos quais 41 milhões destinados à área da liquefacção, 67 milhões à área da combustão (em particular, a combustão em leito fluidizado) e 122 milhões à área da gaseificação. Aliás, foi o trabalho realizado no âmbito dos gaseificadores pressurizados que se veio a revelar da maior importância no desenvolvimento das tecnologias "limpas do carvão".

Em princípios da década de 1970 época em que 0 interesse se centrava principalmente na produção de sucedâneo de gás natural e de outros químicos industriais, existiam em todo o mundo mais de 20 concepções de gaseificadores de oxigénio pressurizado em diferentes fases de desenvolvimento. Embora muitos destes projectos nunca vissem a luz do dia, a União Europeia pode congratular-se por ter concedido o seu apoio a três de entre eles, todos de diferente concepção, que atingiram recentemente a fase de comercialização. Produto da Rheinbraun, o Gaseificador Winkler de Alta Temperatura visa fundamentalmente a gaseificação de lenhite bruta; desenvolvido e ensaiado durante vários anos até 1990, numa central a lenhite com um consumo de 1.500 toneladas/dia, este gaseificador opera à temperatura de $1.000^{\circ} \mathrm{C}$ e à pressão de 120 bar, para uma produção de 37.000 $\mathrm{Nm}^{3} /$ hora de gás de potência calorífica média. Desenvolvido pela British Gas e pela Lurgi, o Gaseificador BGL constitui uma versão pressurizada do bem conhecido sistema Lurgi de contra-corrente em leito fixo, em que as cinzas são removidas como escória fundida à temperatura obtida através da injecção de uma mistura de vapor e de oxigénio na secção inferior do leito; este modelo foi alvo de um rigoroso programa de ensaios, já concluído, no qual foi utilizada uma pequena unidade comercial, com um consumo da ordem das 600 toneladas diárias. Presentemente, a Comissão continua a prestar o seu apoio ao aperfeiçoamento do processo PRENFLO, uma versão pressurizada do processo Koppers-Totzek de caudal arrastado, em que o carvão pulverizado é injectado numa câmara de combustão com oxigénio suficiente para provocar a sua oxidação parcial numa reacção de chama a temperaturas superiores a $2.000^{\circ} \mathrm{C}$ e a pressões entre 24 e 30 bar. A demonstração prática deste processo foi realizada 
numa central de carvão de 48 toneladas/dia, concebida e construída para 0 efeito pela Krupp-Koppers. Ao longo de mais de 8.000 horas de funcionamento, esta central revelou-se bem sucedida na gaseificação de vários tipos de combustiveis sólidos, comprovando as caracteristicas de segurança e economia do sistema, assim como as suas virtudes na perspectiva da protecção ambiental. No campo da combustão do carvão, todas, senão mesmo todas, as principais tecnologias de combustão limpa foram promovidas no âmbito deste programa. A combustão em leito fluidizado foi sujeita a ensaios segundo os métodos de borbulhamento, circulação e pressurização, merecendo referência especial o projecto de Carling (França), de 125 MWe, concebido pela Charbonnages de France segundo 0 processo Lurgi e construído pela Stein Industrie, cujo desempenho se revelou suficientemente convincente para que fosse proposta a construção de várias outras unidades baseadas na mesma concepção (ver a secção seguinte).

No que diz respeito ao sistema de leito fluidizado pressurizado, diversos projectos de mérito, aliás bem conhecidos, beneficiaram do apoio financeiro da Comissão, a qual financiou ainda o único projecto da UE a atingir a dimensão de $75 \mathrm{MW}(\mathrm{e})$ - projecto ENDESA/Babcock Española, realizado em Espanha, com base no processo ABB. 0 apoio financeiro da Comissão foi também extensivo a diversos projectos no âmbito da protecção ambiental associados à utilização de carvão. Para mais detalhes sobre todos os projectos financiados pela Comissão, consultar a base de dados SESAME ou, em alternativa, solicitar ao autor a nova versão impressa do catálogo SESAME, consagrado aos combustiveis sólidos e elaborado a partir da referida base de dados.

\section{O PROGRAMA THERMIE (1990-1994)}

Em 1990, a Comissão transferiu para o programa THERMIE todos os mecanismos de apoio à promoção de novos processos particularmente "limpos" de combustão e conversão de carvão. De natureza globalizante, este programa visa 0 desenvolvimento e o estudo das potencialidades de novas tecnologias aplicadas a todo o sector da energia, enquanto elementos essenciais de uma base energética sólida a implantar na Europa, em resposta às novas solicitações económicas e industriais decorrentes da integração do mercado interno. Concebido para uma duração de 4 anos (1990-1994), o programa THERMIE foi dotado com uma verba de 700 milhões de ECU, dividida por 4 áreas de trabalho: utilização racional da energia, energias novas e renováveis, exploração e produção de hidrocarbonetos e, finalmente, mas não menos importante, combustíveis sólidos. No âmbito deste programa, todas as propostas relativas aos combustiveis sólidos vêem-se obrigadas a competir com propostas para as três restantes áreas, em consequência do que os apoios são concedidos apenas àquelas tidas como técnica e economicamente viáveis, sendo ainda condições prévias de aprovação que os processos envolvidos se mostrem seguros e capazes de respeitar as normas de protecção ambiental.

Os projectos apoiados pelo programa THERMIE podem visar 0 aperfeiçoamento ou a implementação de técnicas, processos ou projectos de caracteristicas inovadoras que, uma vez concluída a fase de investigação e desenvolvimento, se tenham revelado promissores - neste caso, 0 apoio financeiro concedido pela Comissão pode ir até $40 \%$ da componente inovadora. Quando se tratar da demonstração de processos ou produtos já comprovados na União Europeia, seja na sequência de alterações de carácter técnico, seja num outro estado da UE, sob condições económicas ou geográficas diferentes (projecto de dissemina-ção), o apoio é limitado a 35\% dos custos elegiveis.

Assim, a gama de tópicos dentro da área da combustão e da conversão do carvão visada pelo apoio da Comissão, dependerá em larga medida das propostas apresentadas. No entanto, o programa THERMIE contempla também a possibilidade de, sempre que a Comissão considerar conveniente 0 desenvolvimento de um campo específico, esta poder avançar com uma proposta de trabalho própria, estimulando várias partes interessadas a conjugar esforços nesse sentido. Relativamente a este tipo de iniciativas, o exemplo mais relevante é o projecto da central de Ciclo Combinado Integrado (IGCC), a construir em Puertollano (Espanha), o qual será abordado sucintamente na secção seguinte deste trabalho.
Na área da Combustão em Leito Fluidizado Circulante, a Comissão Europeia concedeu o seu apoio financeiro a um grande e interessante projecto proposto conjuntamente pela Charbonnages de France e pela Electricité de France e apoiado tecnologicamente pela Lurgi e pela Stein Industrie. Trata-se de uma central de 250 MWe a construir em Gardanne (França) que, como característica inovadora, apresenta uma câmara de combustão bifurcada na sua metade inferior. Esta configuração visa garantir que 0 ar secundário injectado penetra a toda a largura do caudal de gás, permitindo uma boa mistura entre 0 gás e as partículas sólidas.

A unidade de 50 MWe presentemente em construção nas Astúrias (Espanha) constitui outro exemplo da aplicação do conceito de leito fluido circulante na utilização de combustiveis pobres. Também aqui, as componentes inovadoras do sistema foram objecto do apoio da Comissão. Esta instalação destina-se a queimar uma mistura de residuos mineiros - residuos de hulha, restos de madeira e carvão de baixa qualidade - com conteúdos de cinzas na ordem dos $65 \%$. Do tipo Foster Wheeler, esta unidade foi construída pela Babcock Wilcox España, empreiteiro geral da Hunosa - a companhia mineira local que irá explorar a instalação.

Os apoios da Comissão são extensiveis a outros projectos em que se pretende fazer a demonstração prática das tecnologias envolvendo processos de combustão com baixas emissões de óxidos de carbono e diversas medidas de carácter primário para redução das mesmas. De referir também a promoção de tecnologias de utilização ou eliminação dos resíduos resultantes dos vários processos de combustão de carvão. Para mais detalhes, aconselhamos a consulta do catálogo SESAMO, já referido anteriormente.

\section{A PARTICIPAÇ̃̃O DA UNIÃO EUROPEIA NA PROJECTO PUERTOLLANO}

A principal vantagem exibida pelo processo IGCC (Ciclo Combinado Integrado) encontra-se, muito provavelmente, no baixo nivel de emissões. De facto, as limitações impostas às emissões de óxidos de enxofre, particularmente no caso de centrais de grande capacidade. são, já hoje, severas $\left(400 \mathrm{mg} / \mathrm{Nm}^{3}\right)$. Se por um lado, é previsível que, no futuro. 
venham a ser impostos limites ainda mais rigorosos, por outro, não existem dúvidas de que o sistema IGCC será capaz de os respeitar. De facto, encontra-se, actualmente, disponivel uma série de processos amplamente comprovados de remoção de compostos de enxofre dos gases de combustão, sendo mesmo possivel atingir taxas de dessulfitação superiores a $90 \%$; aliás, prevê-se que possam vir a ser alcançados níveis de emissão inferiores a $10 \mathrm{mg} / \mathrm{Nm}^{3}$. Quanto aos óxidos de azoto presentes nos gases de combustão, estes têm duas origens: compostos de azoto contidos no carvão e reacção na chama do ar atmosférico. Os primeiros podem ser quase totalmente removidos durante a fase de purificação a frio do gás, enquanto a formação de óxidos de azoto durante o processo de combustão pode ser limitada por meio da diluição do gás de combustão em vapor de água e/ou em azoto.

Por conseguinte, o sistema IGCC garante a viabilidade da combustão do carvão com emissões muito reduzidas de óxidos de enxofre e azoto e de poeiras (ver, na Figura 9, o quadro comparativo entre diversos sistemas de queima de carvão).

Figura 9 - Emissôes de SOx, NOx e poeiras em centrais a carvão

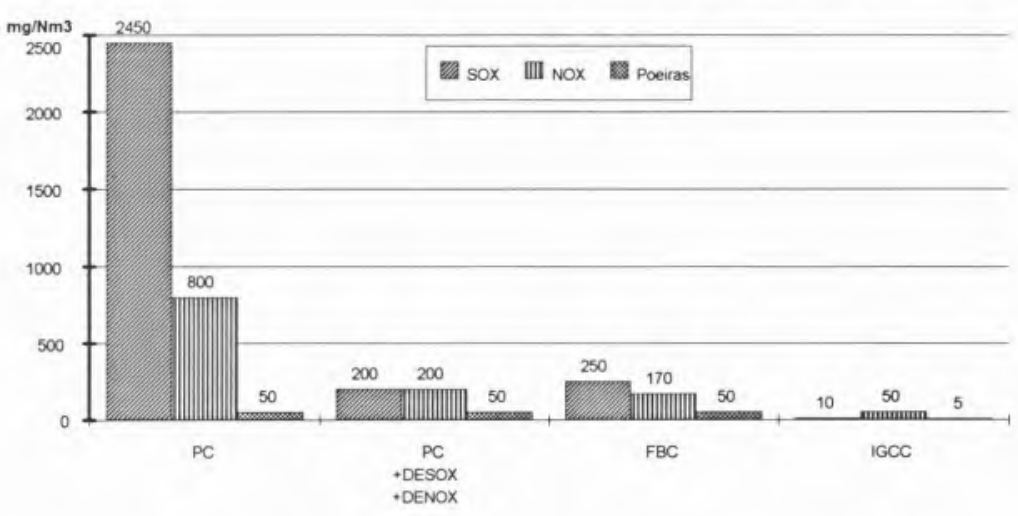

Actualmente, o sistema IGCC constitui a melhor tecnologia de redução das emissões de $\mathrm{CO}_{2}$, conseguindo-0 através de uma combustão mais eficien- são óbvias as vantagens de natureza técnica e comercial que o desenvolvimento de um tal sistema traria aos países da União Europeia. É nesta perspectiva que a Comissão tem vindo a considerar, desde há alguns anos, a necessidade de promover um projecto piloto com a finalidade de divulgar, à escala da União Europeia, os conhecimentos técnicos envolvidos.

No entanto, um tal projecto, envolvendo uma central relativamente grande (pelo menos, na ordem dos 200$300 \mathrm{MWe}$ ) implica investimentos de cerca de 400-550 milhões de ECU. Ora, sejamos realistas, a Comissão não tem, de momento, capacidade para apoiar mais que um projecto, o que, conforme já foi referido, implica a necessidade de fazer opçōes difíceis entre tecnologias e/ou configurações alternativas. Assim, se bem que a Comissão tenha o dever (e a vontade) de apoiar projectos envolvendo a participação e acesso às tecnologias do máximo número possível de países e empresas da EU, não deixa de ser verdade que 0 apoio financeiro da União Europeia, limitado, como se impõe, aos aspectos inovadores dos projectos, obrigará os agentes económicos e governos promotores dos mesmos à obtenção de financiamentos volumosos.

Foi neste contexto que a Comissão organizou várias reuniões com compa-

nhias de electricidade da União Europeia, na sequência das quais seriam formuladas e avaliadas diversas propostas. Finalmente, foi decidido apoiar a proposta de construção da central piloto em Espanha, mas numa base de participação conjunta à escala europeia, com 0 concurso de diversas companhias de serviços públicos de vários paises membros.

Assim, o projecto Puertollano recebeu inicialmente 0 apoio de diversas companhias de electricidade, incluindo "limpa do carvão" bem comprovada e aplicável em centrais eléctricas. De facto, as companhias espanholas ENDESA, IBERDROLA II, SEVILLANA DE ELECTRICIDAD e HIDROELECTRICA DEL CANTABRICO e, ainda, a ELECTRICITÉ DE FRANCE e a ELECTRICIDADE DE PORTUGAL, reunidas numa companhia ad hoc, a ELCOGAS. Mais tarde, em finais de 1992, juntou-se-Ihes a companhia italiana ENEL, à qual se seguiria, em Junho de 1993, a NATIONAL POWER. A actual estrutura do capital da ELCOGAS é ilustrada pelo quadro seguinte:

\section{QUADRO 1: ACCIONISTAS DA ELCOGAS}

\begin{tabular}{lr}
\hline ENDESA & $30,53 \%$ \\
ELECTRICITÉ DE FRANCE & $29,13 \%$ \\
IBERDROLA & $11,10 \%$ \\
SEVILLANA DE ELECTRICIDAD & $7,40 \%$ \\
HIDROELECTRICA DEL & \\
$\quad$ CANTABRICO & $4,00 \%$ \\
ELECTRICIDADE DE PORTUGAL & $4,00 \%$ \\
ENEL & $4,00 \%$ \\
NATIONAL POWER & $4,00 \%$ \\
BABCOCK WILCOX ESPAÑOLA & $2,50 \%$ \\
SIEMENS & $2,34 \%$ \\
KRUPP KOPPERS & $1,00 \%$ \\
\hline
\end{tabular}

A proposta consiste na construção de uma central para queima de carvões betuminosos de produção local ou importados, com uma produção liquida de 305 MWe (337 MWe de potência bruta) e um rendimento (com base na utilização de carvão local) da ordem dos 44,5$45,5 \%$ (ISO). As emissões de dióxido de enxofre (a $15 \%$ de $\mathrm{O}_{2}$ ) serão inferiores a $10 \mathrm{mg} / \mathrm{Nm}^{3}$, enquanto as de óxidos de azoto não atingirão os $60 \mathrm{mg} / \mathrm{Nm}^{3}$. Além disso, e devido à maior eficiência deste tipo de instalação, as emissões de dióxido de carbono serão aproximadamente $80 \%$ das observadas numa central de concepção convencional.

Decisões importantes, foram as tomadas, em Agosto de 1992, relativamente à selecção do gaseificador e das turbinas de gás e de vapor. A ELCOGAS optou pelo gaseificador PRENFLO da Krupp-Koppers, e pela Siemens como responsável pelo ciclo e pelas turbinas. Orçamentado em cerca de 600 milhões de ECU, este projecto prevê que a central atinja as fases de arranque em meados de 1995 (a gás natural) e meados de 1996 (a carvão).

Espera-se que, ao longo de uma periodo de demonstração de três anos, seja possivel confirmar a eficiência, disponibilidade e rendimento da 
ESTABILIDADE DE PREÇOS

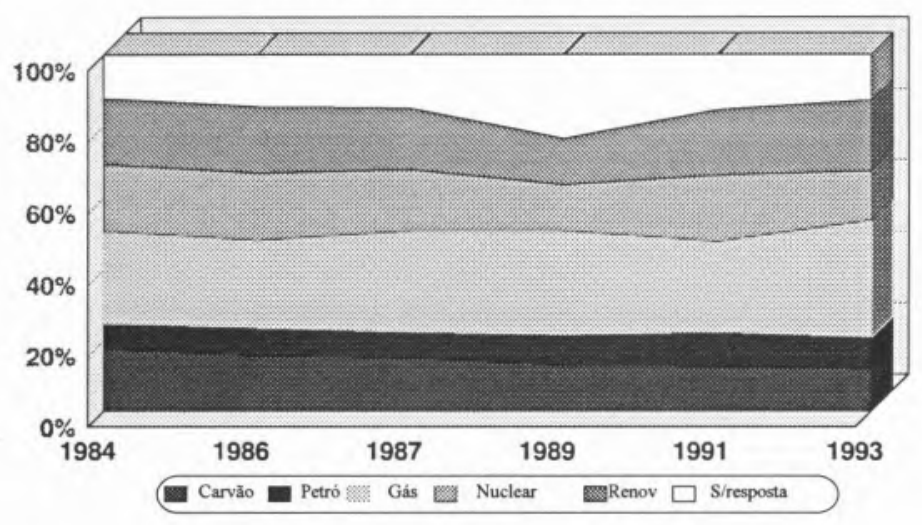

GARANTIA DE FORNECIMENTO

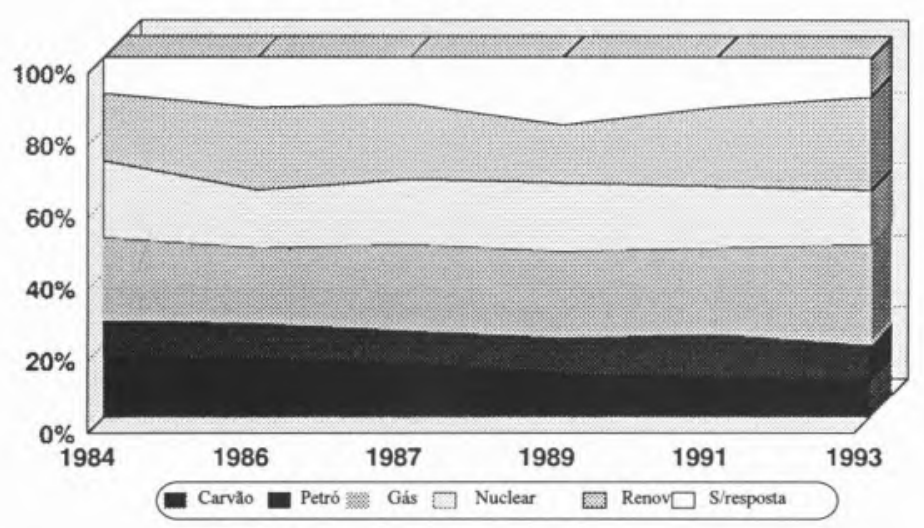

MENOS POLUIÇÃO

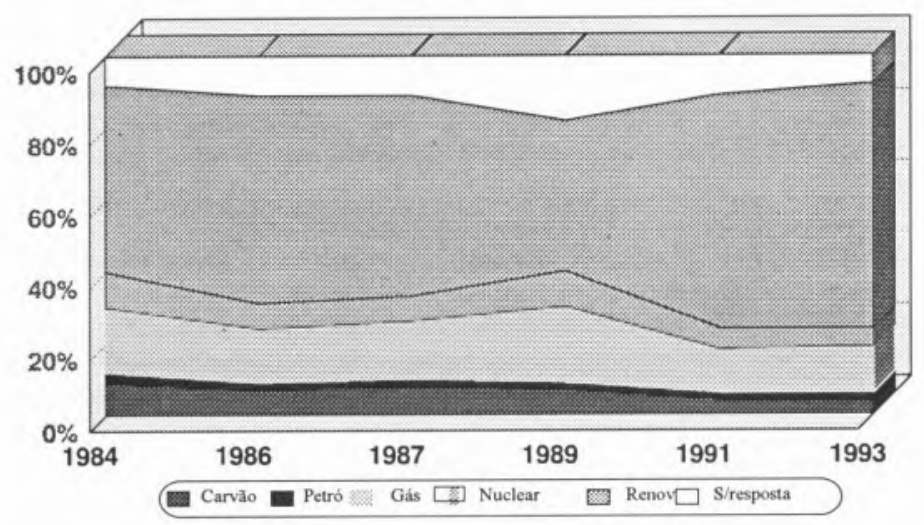

Figura 10: Opinião püblica sobre questōes energéticas (fontes: Comissão/Eurobarómetro)

central em condições de exploração contínua e, também, avaliar o desempenho do gaseificador com diversos tipos de carvão, quer importados, quer de produção local.

Em conclusão, a Comissão pensa tratar-se de um projecto europeu da maior importância (e merecedor de todo 0 apoio da União Europeia), no qual deposita as suas esperanças no sentido de que venha a demonstrar que 0 carvão pode ser utilizado na produção de electricidade de uma forma limpa, altamente eficiente e de aceitação generalizada.

\section{O CARVÃo E A OPINIÃO PÚBLICA}

Conforme já foi demonstrado, não será possivel, nas próximas décadas, prescindir do carvão no sector da produção de electricidade. No entanto, a imagem que a opinião pública faz deste combustivel nunca foi tão negativa. Assim, e já que se levantam inquietações a vários níveis, será de toda a conveniência enfrentar esta situação, de modo a garantir a continuidade do recurso ao carvão, pelo menos como uma alternativa. A opinião pública não tem consciência, nem da necessidade da utilização do carvão, nem dos progressos registados nos últimos anos a nível de redução da poluição provocada. Contudo, os factos são patentes: graças aos esforços conjugados dos sectores industriais da UE envolvidos, às iniciativas dos países membros e aos programas das Comunidades Europeias, a situação na UE apresenta-se hoje drasticamente diferente da observada na antiga Europa de Leste.

A Comissão está a levar a cabo uma série de inquéritos visando avaliar a atitude dos Europeus relativamente às questões associadas à energia. As 3 figuras seguintes ilustram que não só a imagem do carvão é muito negativa, como também se tem vindo a deteriorar ao longo dos anos. 0 mais surpreendente não é o facto de as populações pensarem que 0 carvão é poluidor, mas sim, de 0 verem como um combustivel dispendioso e pouco fiável a nível de fornecimentos.

É óbvio que organismos como a Comissão, responsáveis pela adopção das políticas energéticas deverão tentar esclarecer devidamente a opinião pública e, também, mentalizar as populações no sentido da aceitação de novas centrais eléctricas a carvão, até que as energias renováveis possam oferecer uma resposta substancial à procura de energia. 